\title{
Internado médico durante la pandemia del COVID-19: la problemática de los practicantes prepofesionales de medicina ante la legislación peruana
}

\section{Medical internship during the COVID-19 pandemic: the problem of pre-professional medical practitioners in the face of Peruvian legislation}

Correspondencia Fitzgerald Aquiles Arroyo Ramirez fitzgeraldaquilesarroyoramirę@gmail.com

Recibido: 29/09/2020 Aprobado: 17/12/2020

Citar como: Arroyo-Ramirez FA, Rojas-Bolivar D. Internado médico durante la pandemia del COVID-19: la problemática de los practicantes prepofesionales de medicina ante la legislación peruana. Acta Med Peru. 2020;37(4):562-4. doi: https://doi.org/10.35663/ amp.2020.374.1852
Fitzgerald A. Arroyo-Ramirez ${ }^{1,2, a}$, Daniel Rojas-Bolivar ${ }^{3, b}$

Asociación para el Desarrollo de la Investigación Estudiantil en Ciencias de la Salud (ADIECS). Universidad Nacional Mayor de San Marcos. Lima, Perú.

Centro de Investigaciones Tecnológicas, Biomédicas y Medioambientales. Callao, Perú.

Autor independiente. Lima, Perú.

Estudiante de medicina; ${ }^{\mathrm{b}}$ médico cirujano

\section{Sr. Editor,}

Cada año miles de estudiantes de medicina realizan sus prácticas pre-profesionales en diversos establecimientos de salud del Perú, durante el último año de su formación; estas prácticas se denominan internado de medicina ${ }^{[1]}$. En este periodo, se consolida lo aprendido en años anteriores, además que representa un requisito para obtener el título profesional ${ }^{[2]}$.

Sin embargo, las condiciones laborales del internado se caracterizan por la sobrecarga de trabajo, el maltrato y la precariedad ${ }^{[3,4]}$. La jornada laboral promedio de un interno de medicina (IM) es de aproximadamente 10 horas diarias, pero se puede prolongar hasta 36 horas sin descanso ${ }^{[3,4]}$. El $42,5 \%$ de egresados refirió no haber descansado luego de las guardias nocturnas en ninguna de sus rotaciones ${ }^{[1]}$. Asimismo, 3 de cada 4 egresados de medicina refirieron haber sido víctimas de algún tipo de agresión verbal, física o sexual durante el internado ${ }^{[1]}$. Además, el $85 \%$ de los IM han reportado accidentes con sustancias biológicas u objetos punzocortantes ${ }^{[2]}$. A pesar de los constantes riesgos biológicos, sólo la mitad de los IM tuvieron acceso a algún seguro de salud, y solo 16,4\% recibió un seguro por parte de la institución donde laboraba ${ }^{[1]}$. Además, casi el $40 \%$ de los IM no reciben ningún tipo de remuneración por su actividad y a otro importante grupo se le incumple su derecho a la alimentación ${ }^{[1,3]}$.

En este contexto, la normativa que regula a los IM en el Perú se puede observar en la Tabla 1. Esta normativa presenta vacíos respecto a los derechos de los IM y su cumplimiento, tanto en el aspecto formativo como en el laboral ${ }^{[5]}$. Actualmente, las actividades de los IM se encuentran suspendidas por más de cinco meses desde el inicio de la emergencia sanitaria a causa de la pandemia de la COVID-19 ${ }^{\left[{ }^{[5]}\right.}$. La Asociación Nacional de Facultades de Medicina (ASPEFAM) siguió las indicaciones de la Resolución Viceministerial 081-2020-MINEDU y decidió recomendar el retiro de los internos de medicina de los establecimientos de salud, dada su condición de estudiantes de último año y que no contaban con equipos de protección personal (EPP) y seguros ${ }^{[5]}$. El 15 de agosto pasado, se promulgó el Decreto de Urgencia $\mathrm{N}^{\circ}$ 090-2020, el cual estableció la reanudación de actividades del internado como medida para el cierre de brechas de recursos humanos frente a la pandemia, que establece derechos temporales como un estipendio no menor a la remuneración mínima vital de 930 soles, EPP y seguro de salud y vida. Sin embargo, no 
Tabla 1. Marco legal acerca de prácticas preprofesionales y el internado en el Perú.

Normativa Año Nombre Derechos y deberes

\begin{tabular}{|c|c|c|c|}
\hline $\begin{array}{l}\text { Decreto } \\
\text { Supremo } \\
\mathrm{N}^{\circ} 020-2002-\mathrm{EF}\end{array}$ & 2002 & $\begin{array}{l}\text { Compensación } \\
\text { remunerativa mensual } \\
\text { para internos de } \\
\text { medicina humana y } \\
\text { odontología }\end{array}$ & $\begin{array}{l}\text { Establece la compensación } \\
\text { remunerativa mensual de } 400 \text { soles } \\
\text { (\$111.34) y aguinaldo en Fiestas } \\
\text { Patrias y Navidad. }\end{array}$ \\
\hline Ley N ${ }^{\circ} 28518$ & 2005 & $\begin{array}{l}\text { Ley sobre modalidades } \\
\text { formativas laborales }\end{array}$ & $\begin{array}{l}\text { Define los tipos de modalidades } \\
\text { formativas entre ellas las prácticas } \\
\text { pre-profesionales cuyo ámbito de } \\
\text { aplicación es la actividad privada. }\end{array}$ \\
\hline $\begin{array}{l}\text { Decreto Supremo } \\
\mathrm{N}^{\circ} 007-2005-\mathrm{TR}\end{array}$ & 2005 & $\begin{array}{l}\text { Reglamento de la } \\
\text { Ley N } N^{\circ} 28518 \text { "Ley } \\
\text { sobre Modalidades } \\
\text { Formativas Laborales" }\end{array}$ & $\begin{array}{l}\text { Establece la remuneración, la cual } \\
\text { no debe ser menor a la mínima vital, } \\
\text { además de una subvención adicional } \\
\text { cada } 6 \text { meses. }\end{array}$ \\
\hline $\begin{array}{l}\text { Decreto Supremo } \\
N^{\circ} 003-2008-T R\end{array}$ & 2008 & $\begin{array}{l}\text { Dictan medidas sobre } \\
\text { jornadas máximas de } \\
\text { modalidades formativas } \\
\text { reguladas por la Ley } \\
\mathrm{N}^{\circ} 28518 \text { internado en } \\
\text { ciencias de la salud. }\end{array}$ & $\begin{array}{l}\text { Establece la jornada máxima de } 6 \\
\text { horas diarias o } 150 \text { horas mensuales, } \\
\text { incluyendo las guardias nocturnas. } \\
\text { Establece el régimen de guardias } \\
\text { nocturnas y los descansos pre y post } \\
\text { guardia. }\end{array}$ \\
\hline
\end{tabular}

Se cumplía parcialmente en algunos establecimientos de salud previo al inicio de la pandemia (aproximadamente del $60 \%$ de los internos era remunerado). Actualmente este DS se encuentra suspendido mientras dure la emergencia sanitaria por el COVID-19.

No aplica a todos, solo para los establecimientos privados.

No aplica a todos, solo a ESSALUD y establecimientos privados.

No se cumple. El interno trabaja más de las horas establecidas y no se reconocen sus descansos pre y post guardia. Existen diversas opiniones sobre el tiempo efectivo para una formación médica de calidad en los establecimientos de salud, así como el desarrollo de labores no propias a la formación profesional (labores administrativas y auxiliares).

Decreto Legislativo que aprueba el régimen

Decreto Legislativo No 1401

Decreto de Urgencia $\mathrm{N}^{\circ} 090-2020$ 2018 especial que regula las modalidades formativas de servicios en el sector público

Decreto de Urgencia que establece medidas excepcionales y temporales que coadyuven al cierre de brechas de recursos humanos en salud para afrontar la pandemia por la COVID -19
Establece el régimen especial que regula las modalidades formativas en el sector público, en la que incluye horarios, seguro de salud y remuneración no menor a la remuneración mínima vital.

Se exceptúa de este DL al internado de ciencias de salud.

Establece la reanudación progresiva al internado, durante el cual, de manera excepcional, se les otorgarán los EPP a los internos, asimismo, mientras dure la emergencia sanitaria, tendrán derecho a un estipendio equivalente y no menor a una remuneración mínima vital de 930 soles (\$258.87), un seguro de salud y seguro de vida.
No aplica, pues se exceptúa a los internos de ciencias de la salud en sus disposiciones complementarias.

Se aplicaría para los internos mientras dure la emergencia sanitaria, sin embargo, a la fecha el personal sanitario sufre de desabastecimiento de EPP, falta de pago y el alto número de víctimas. A través de este DU queda suspendido el DS $\mathrm{N}^{\circ} 020$ 2002-EF, el cual establecía la compensación remunerativa mensual.

DL: decreto legislativo, DS: decreto supremo, DU: decreto de urgencia, EPP: equipo de protección personal, TR: normas del Ministerio de Trabajo y Promoción del Empleo, EF: normas del Ministerio de Economía y Finanzas. 
especifica si los derechos otorgados continuarán después del estado de emergencia, además que no se está cumpliendo con el personal asistencial (déficit en cantidad y calidad de los EPP e incumplimiento de pagos y bonos); asimismo, no se considera la situación de salud de los internos, no se contempla si presentan factores de riesgo o comorbilidades, lo cual ha conllevado a los gremios estudiantiles a pronunciarse ${ }^{[5]}$.

Consideramos que es necesario formular una ley o reglamento de prácticas pre-profesionales de ciencias de la salud que defina adecuadamente los derechos y obligaciones de los IM y otras carreras de salud. También sostenemos que la larga suspensión de las actividades responde a la falta de condiciones mínimas de los IM, además de las deficiencias de los sectores educación y salud, pero sobre todo a la falta de normativas alrededor del internado que garanticen que sea digno, de calidad y que proporcione las herramientas adecuadas para la formación médica dentro del marco de la seguridad y salud de los IM y sus familias.

Contribuciones de autoría: FAAR y DRB concibieron la idea de esta carta al editor, redactaron el manuscrito, revisaron y aprobaron la versión final.

Potenciales conflictos de interés: los autores declaran no tener conflictos de interés.

Fuentes de financiamiento: autofinanciado.

\section{ORCID}

Fitzgerald A. Arroyo-Ramírez, https://orcid.org/0000-00018541-2685

Daniel Rojas-Bolívar, https://orcid.org/0000-0003-0585-4155

\section{REFERENCIAS BIBLIOGRÁFICAS}

1. Nieto-Gutierrez W, Taype-Rondan A, Bastidas F, Casiano-Celestino $\mathrm{R}$, Inga-Berrospi F. Percepción de médicos recién egresados sobre el internado médico en Lima, Perú 2014. Acta Med Peru. 2016;33(2):105-10.

2. Charca-Benavente LC, Huanca-Ruelas GH, Moreno-Loaiza O. Biological accidents in last-year medical students from three hospitals in Lima Peru. Medwave. 2016;16(7):e6514. doi:10.5867/ medwave.2016.07.6514

3. Galán-Rodas E, Díaz-Vélez C, Maguiña Várgas C, Villena Vizcarra J. Bioseguridad durante el Internado de Medicina en Hospitales de Trujillo - La Libertad 2010: a propósito de la muerte de un estudiante de medicina. Acta Med Peru. 2010;27(2):119-22.

4. Rojas-Bolivar D. Diario de un interno de medicina: aproximaciones a la educación médica y al sistema de salud en Lima, Perú. 1. ${ }^{a}$ ed. Lima: Instituto de Estudios Peruanos; 2018.

5. Cárdenas A. "No seamos cómplices del abuso", internos de Medicina rechazan decreto que los coloca de vuelta en los hospitales. La Republica [Internet]. 2020 [citado 13 de agosto de 2020]; Disponible en: https://larepublica.pe/sociedad/2020/08/04/coronavirus-enperu-internos-de-medicina-rechazan-decreto-que-establece-suretorno-a-los-hospitales-ministerio-de-salud-atmp/ 